\title{
Prognostic Significance of Ki-67 and p53 Immunoexpression in Breast Carcinoma Patients with Positive Axillary Lymph Nodes
}

\author{
Lalit Sharma ${ }^{1}$, Kafil Akhtar ${ }^{1 *}$, Syed Shamshad Ahmad ${ }^{1}$ and Atia Zakaur Rab ${ }^{2}$ \\ 'Department of Pathology, Jawaharlal Nehru Medical College, Aligarh Muslim University, Aligarh. (U.P)-India. \\ ${ }^{2}$ Department of General Surgery, Jawaharlal Nehru Medical College, Aligarh Muslim University, Aligarh. (U.P)-India.
}

\begin{abstract}
Introduction: Breast carcinoma is a heterogenous disorder in which the treatment modality should be based on a risk assessment approach and only patients with higher relative risk of recurrence and distant metastasis should be the appropriate candidates for adjuvant therapy. This is where role of prognostic variables like Ki-67 and p53 immunoexpression as biomarkers of proliferative activity of tumor cells becomes important.
\end{abstract}

Aims and Objectives: The aim of this study was to evaluate the significance of Ki-67 and p53 immunoexpression as prognostic biomarkers in breast carcinoma patients with positive axillary lymph nodes.

Material and Methods: A total of 182 breast cancer patients were included in the study, assessed for various clinicopathological characteristics and after receiving the mastectomy/lobectomy specimen, tissue sections about $1 \mathrm{~cm}$ thick were taken from representative areas, processed in an automated tissue processor (Histokinette) and simultaneously stained for routine hematoxylin and eosin stain along with Ki-67 and p53 immunostains and patients followed up.

Results: High Ki-67 and p53 immunoexpression was significantly associated with larger tumor size, higher tumor grade, axillary lymph node metastasis, higher disease stage at presentation, lymphovascular invasion, early recurrence, shortened disease free survival and worse overall survival.

Conclusions: Ki-67 and p53 immunoexpression can be used as a surrogate biomarker along with other clinicopathological characteristics in resource constrained facilities for better prediction of prognosis of breast cancer patients with positive axillary lymph nodes.

Keywords: Ki-67, p53, Biomarker, Breast Cancer, Positive Axillary Lymph Nodes.

\section{Introduction}

Breast cancer is the leading cause of female mortality and morbidity worldwide today. In 2017, almost 2,55,000 new cases of invasive breast carcinoma were diagnosed in the United States of America with more than 40,000 women and 400 men succumbing to this menace. Of these, more than 30000 women aged below 40 years. Almost 6 million breast cancer survivors are present globally with nearly half of them residing in the United States of America.[1]

With the current trend and regular hike in incidence rate, projected number of breast cancer cases for India till 2020 may go as high as 1.8 million with its relative percentage remaining same among all the cancer groups.[2] Cervical cancer has led the race as being the commonest malignancy found in Indian women, but breast carcinoma has overtaken it as being the most common cancer in urban India, where it constitutes $>30.0 \%$ of all cancers in females; the main culprit being westernised lifestyle and the change in reproductive behaviour. Breast cancer is a growing problem in India with a rise in incidence of $0.5 \%-2.0 \%$ per year seen across whole nation in all age groups but more in the younger age groups ( $<45$ years).[3] Breast cancer was the most common cancer among Indian females with age adjusted incidence rate as high as 25.8 and mortality rate of 12.7 per 100,000 women.[2]

Axillary lymph node positivity in breast carcinoma cases has been a proven bad prognostic variable related to worse outcome and decreased survival and thus, patients with metastasis to axillary lymph nodes are probable candidates for adjuvant chemotherapy. The prognosis becomes grim as the number of axillary lymph nodes involved increases.[4] But not all patients should qualify to receive the chemotherapeutic modality and succumb to its adverse effects, as breast carcinoma is a heterogenous disorder in which the treatment modality should be based on a risk assessment approach and only patients with higher relative risk of recurrence and distant metastasis should be the appropriate candidates for adjuvant therapy. This is where role of prognostic variables like Ki-67 and p53 immunoexpression as biomarkers of proliferative activity of tumor cells becomes important. These variables have been extensively studied in in node negative breast 
carcinoma patients but their significance in node positive breast carcinoma patients has been controversial and unclear.[5,6]

$\mathrm{Ki}-67$ is a nuclear non histone protein and a biomarker for prognosis and sensitivity of cancer cells to endocrine therapy/chemotherapy dictating spread and invasion of breast cancer. Ki-67-positive breast cancers are more actively growing, more aggressive and more metastatic. [7,8] Initially studies regarding role of p53 in breast cancers were based on identification of p53 using immunohistochemistry but the prognostic significance couldn't be elucidated, so sequencing studies for p53 mutation were done which showed strong correlation between $\mathrm{p} 53$ overexpression and reduced OS and DFS.[9]

This study evaluated the prognostic significance of Ki-67 and p53 immunoexpression in axillary lymph node positive breast carcinoma patients and analysed their association with other clinicopathologic characteristics.

\section{Material and Methods}

A total of 182 breast carcinoma patients who presented in Jawaharlal Nehru Medical College and Hospital, Aligarh Muslim University, Aligarh (U.P.) from 2012 to 2017, met the inclusion criteria. A detailed history was obtained, following which the patient was subjected to thorough clinical examination and proper work up. After receiving the mastectomy/lobectomy specimen, tissue sections about $1 \mathrm{~cm}$ thick were taken from representative areas, processed in an automated tissue processor (Histokinette) and simultaneously stained for routine hematoxylin and eosin stain along with Ki-67 and p53 immunostains.

Ki-67 expression was evaluated as the percentage of positively stained malignant cells showing clear nuclear staining using the antihuman Ki-67 monoclonal antibody MIB1.[10] A quantitative analysis was made at high power ( $\mathrm{x} 40$ objective) by counting 500 tumor cells within representative fields. All nuclei with homogenous granular staining, multiple speckled staining or nucleolar staining were counted as positive, regardless of staining intensity. Cells with cytoplasmic staining were excluded. Ki-67 antigen expression was evaluated as low, intermediate and high with $<14 \%, 14 \%-30 \%$ and $>30 \%$ malignant cells showing nuclear positivity.[11] Epithelial p53 immunoexpression was evaluated in 100 cells (nuclei)/ sample with ready to use anti p53 antibody (Thermo, clone DO-7). Finally the sections were incubated with diaminobenzidine tetrahydrochloride (DAB) in hydrogen peroxide substrate and imidazole for $10 \mathrm{~min}$. The sections were counterstained with hematoxylin. p53 expression was evaluated as negative ( $\leq 10 \%$ nuclei stained) and positive $(>10 \%$ nuclei stained).[12]

Follow up was performed by hospital visits, telephonic conversation, house visits and regular clinical examinations after first day of surgery. The main end points were disease recurrence and overall survival. Statistical analysis was performed to evaluate the association of Ki-67 and p53 immunoexpression with other tumor parameters and also with disease recurrence and overall survival (OS). A p-value of less than 0.05 was considered statistically significant.

\section{Results}

The mean age at diagnosis was 50.01 years (range, 1880 years) with 180 females and 02 males. Majority of patients were postmenopausal (61.0\%), above 40 years age (71.0\%), showed tumor size/stage T2 (40.7\%), nodal stage $\mathrm{N} 2(50.5 \%)$, histologic grade 2 carcinoma $(51.6 \%)$, stage III disease at presentation $(70.0 \%)$ and showed evidence of lymphovascular invasion (59.0) (Table 1). Majority of the tumors presented in upper outer quadrant with chief complaints of breast lump followed by accompanying lymphadenopathy, pain in breast, nipple abnormalities, overlying skin involvement and ulceration.

Among the histological subtypes, Invasive ductal carcinoma (NST) $(96.0 \%)$ was the most common subtype encountered followed by Invasive lobular carcinoma $(1.5 \%)$, Medullary carcinoma (1.0\%) and one case each of Metaplastic carcinoma, Invasive mucinous carcinoma and Invasive papillary carcinoma.

The median follow-up period was 30 months (5-55 months) in our study. During the follow up period, $42(23.0 \%)$ patients were lost and were excluded for further evaluation of Ki-67 and p53 immunoexpression with disease free survival and overall survival. Out of remaining 140 patients, a total of $20(14.0 \%)$ patients showed recurrence of breast carcinoma and $18(13.0 \%)$ patients died. (Table 1)

The Ki-67 staining was categorised as low, intermediate and high in $73(40.0 \%), 61(33.5 \%)$ and $48(26.5 \%)$ cases respectively. In our study, out of 45 cases of grade 1 carcinomas, 25 (55.0\%) cases showed low, 18 (40.0\%) cases showed intermediate and $02(5.0 \%)$ cases showed high Ki expression. Out of 43 Grade 3 carcinomas, 11 $(25.0 \%)$ cases showed low, $14(33.0 \%)$ cases showed intermediate and $18(42.0 \%)$ cases showed high Ki expression (Figure 1). There was a statistically significant association between histologic grade and Ki-67 expression $(\mathrm{p}<0.001)$. There was a statistically significant difference in $\mathrm{Ki}-67$ expression in $<40$ year age group as compared to $>40$ year age group $(\mathrm{p}<0.05)$ with higher percentage 
of cases showing high Ki-67 expression in patients above 40 years signifying that breast carcinomas with positive axillary lymph nodes in higher age groups tend to have increased proliferative potential and often metastasize earlier. (Table 2)

Out of 23 cases with $\geq 10$ axillary lymph nodes involved, $21(91.0 \%)$ cases showed high Ki-67 expression and 01 $(4.5 \%)$ case each showed low and intermediate expression. Majority of the tumors with $\leq 3$ positive axillary lymph nodes (64.0\%), showed low Ki-67 expression, while only $05(7.6 \%)$ cases showed high $\mathrm{Ki}-67$ expression in the same category. So it was seen that higher nodal stage was significantly associated $(p<0.0001)$ and positively correlated with increased Ki-67 expression. In the present study, majority of the T3 stage $(41.0 \%)$ and T4 stage (52.0\%) carcinomas showed high Ki-67 expression with vascular invasion (Figure 2 and 3) which was higher than $\mathrm{T} 1$ stage $(11.0 \%$ cases $)$ and $\mathrm{T} 2$ stage $(17.0 \%$ cases $)$ carcinomas in the same category. It was seen that tumor size/stage (T) showed statistically significant association with Ki-67 expression $(\mathrm{p}=0.005)$ indicating that more aggressive the tumor, higher the $\mathrm{Ki}-67$ expression and poorer the prognosis. (Table 2)

Nineteen $(38.0 \%)$ cases out of 50 p53 positive cases showed high Ki-67 expression, while 29 (22.0\%) cases out of 132 p53 negative cases showed similar result, but without a significant statistical difference $(p=0.07)$ attributable to different cut off values and no standardised interpretation scheme for Ki-67 immunoexpression. Ki-67 expression was statistically associated with breast cancer recurrence $(p<0.05)$. It was found that patients with high Ki-67 expression had higher and earlier chances of disease relapse/ progression, thus suggesting Ki-67 a bad prognostic marker in breast cancer patients with positive axillary lymph nodes. A total of 18 patients succumbed to death, out of which $08(44.0 \%)$ cases, 07 (39.0\%) cases and $03(17.0 \%)$ cases belonged to high, intermediate and low Ki-67 expression groups, respectively. While, majority of the patients who succumbed to death showed high $\mathrm{Ki}$ 67 expression, the statistical difference was not significant $(\mathrm{p}=0.13)$. (Table 2)

Out of 182 cases, $132(72.0 \%)$ cases showed negative p53 immunoexpression ( $\leq 10 \%$ nuclei stained), while 50 (28.0\%) cases showed positive p53 immunoexpression. Among histomorphological subtypes, positive p53 expression was seen in $49(28.0 \%)$ cases of IDC (NOS) followed by medullary carcinoma and metaplastic carcinoma, while mucinous carcinoma, invasive lobular carcinoma and papillary carcinoma were p53 negative. There was no significant association between age and p53 expression. Majority of the patients showed negative p53 expression. Below 40 year age group, out of 52 cases $10(19.0 \%)$ cases showed p53 positivity and $42(81.0 \%)$ were negative, while above 40 year age group showed, 40 $(31.0 \%)$ cases as p53 positive and $90(69.0 \%)$ as negative. p53 immunoexpression was statistically significantly associated with histologic grade, nodal stage and pathological stage $(\mathrm{p}<0.05)$. (Table 3 )

Out of 45 grade 1 tumors, $39(86.0 \%)$ cases were p53 negative and only $06(14.0 \%)$ cases were p53 positive, while among rest 137 higher grade tumors, 44 (32.0\%) cases showed p53 positivity (Figure 4). So, there was a rising trend in p53 positivity with increasing histologic grade, which was statistically significant $(\mathrm{p}<0.05)$. p53 expression showed no significant association with lymphovascular invasion. (Table 3)

p53 expression was statistically associated with breast cancer recurrence $(\mathrm{p}<0.05)$ with $17(85.0 \%)$ cases showing p53 positivity out of 20 cases with disease recurrence. Of 18 patients who succumbed to death, $12(67.0 \%)$ cases were p53 positive and $06(33.0 \%)$ cases were negative. Thus, it was seen that high p53 immunoexpression was statistically associated with disease recurrence and worse overall survival, proving p53 a bad prognostic marker in breast cancer patients with positive axillary lymph nodes. (Table 3)

Table 1: Patient characteristics $(n=182)$.

\begin{tabular}{|l|c|}
\hline Characteristics & No. (\%) \\
\hline Age, years [median (range)] & $50.01(18-80)$ \\
\hline$\leq 40$ & $52(29.0)$ \\
\hline$>40$ & $130(71.0)$ \\
\hline Gender & $180(98.9)$ \\
\hline Females & $02(1.1)$ \\
\hline Males & \\
\hline Menopause & \\
\hline
\end{tabular}




\begin{tabular}{|c|c|}
\hline Characteristics & No. (\%) \\
\hline Premenopause & $71(39.0)$ \\
\hline Postmenopause & $109(61.0)$ \\
\hline \multicolumn{2}{|l|}{ Histology } \\
\hline IDC & $174(96.0)$ \\
\hline ILC & $03(1.5)$ \\
\hline Others & $05(2.5)$ \\
\hline \multicolumn{2}{|l|}{ Tumor stage (pT) } \\
\hline $\mathrm{T} 1$ & $39(21.4)$ \\
\hline $\mathrm{T} 2$ & $74(40.7)$ \\
\hline T3 & $44(24.2)$ \\
\hline $\mathrm{T} 4$ & $25(13.7)$ \\
\hline \multicolumn{2}{|l|}{ Nodal stage $(\mathrm{pN})$} \\
\hline N1 & $67(36.8)$ \\
\hline N2 & $92(50.5)$ \\
\hline N3 & $23(12.7)$ \\
\hline \multicolumn{2}{|l|}{ Histologic Grade } \\
\hline 1 (well differentiated) & $45(24.7)$ \\
\hline 2 (moderately differentiated) & $94(51.6)$ \\
\hline 3 (poorly differentiated) & $43(23.7)$ \\
\hline \multicolumn{2}{|l|}{ Lymphovascular invasion } \\
\hline Negative & $74(41.0)$ \\
\hline Positive & $108(59.0)$ \\
\hline \multicolumn{2}{|l|}{ Ki67 labeling index } \\
\hline Low $(<14.0 \%)$ & $73(40.0)$ \\
\hline Intermediate (14.0-30.0\%) & $61(33.5)$ \\
\hline High $(>30.0 \%)$ & $48(26.5)$ \\
\hline \multicolumn{2}{|l|}{ p53 status } \\
\hline Positive (>10\%) & $50(28.0)$ \\
\hline Negative $(\leq 10 \%)$ & $132(72.0)$ \\
\hline \multicolumn{2}{|l|}{ Follow Up } \\
\hline Attrition & $42(23.0)$ \\
\hline Remaining & $140(77.0)$ \\
\hline \multicolumn{2}{|l|}{ Recurrence/Metastasis } \\
\hline Present & $20(14.0)$ \\
\hline Absent & $120(86.0)$ \\
\hline \multicolumn{2}{|l|}{ Overall Survival } \\
\hline No event & $122(78.0)$ \\
\hline Death & $18(22.0)$ \\
\hline
\end{tabular}


Table 2: Association of clinicopathological parameters with Ki-67 expression.

\begin{tabular}{|c|c|c|c|c|c|}
\hline & No. of patients & Low Ki-67 & Intermediate Ki-67 & High Ki-67 & \\
\hline & $\mathrm{N}=182$ & n (\%) & n (\%) & n (\%) & \\
\hline Variables & & & & & P-value \\
\hline Age & & & & & 0.04 \\
\hline$\leq 40$ years & 52 & $28(54.0)$ & $15(29.0)$ & $09(17.0)$ & \\
\hline$>40$ years 130 & $45(35.0)$ & $46(36.0)$ & $39(29.0)$ & & \\
\hline Tumor size/ stage & & & & & 0.005 \\
\hline $\mathrm{T} 1$ & 39 & $24(61.0)$ & $11(28.0)$ & $04(11.0)$ & \\
\hline T2, T3, T4 143 & $49(34.0)$ & $50(35.0)$ & $44(31.0)$ & & \\
\hline Lymph node stage & & & & & $<0.0001$ \\
\hline N1 & 67 & $43(64.0)$ & $19(28.0)$ & $05(8.0)$ & \\
\hline $\mathrm{N} 2, \mathrm{~N} 3$ & 115 & $30(26.0)$ & $42(37.0)$ & $43(37.0)$ & \\
\hline Histologic grade & & & & & 0.0005 \\
\hline 1 & 45 & $25(55.0)$ & $18(40.0)$ & $02(05.0)$ & \\
\hline 2,3 & 137 & $48(35.0)$ & $43(31.0)$ & $46(34.0)$ & \\
\hline LVI & & & & & 0.009 \\
\hline Absent & 74 & $35(47.0)$ & $28(38.0)$ & $11(15.0)$ & \\
\hline Present & 108 & $37(34.0)$ & $33(31.0)$ & $38(35.0)$ & \\
\hline p53 expression & & & & & 0.07 \\
\hline Negative 132 & $60(45.0)$ & $43(33.0)$ & $29(22.0)$ & & \\
\hline Positive & 50 & $13(26.0)$ & $18(36.0) a$ & $19(38.0)$ & \\
\hline \multicolumn{6}{|l|}{ FOLLOW UP } \\
\hline Disease Recurrence & & & & & 0.0002 \\
\hline Present & 20 & $01(05.0)$ & $06(30.0)$ & $13(65.0)$ & \\
\hline Absent & 120 & $50(42.0)$ & $42(35.0)$ & $28(23.0)$ & \\
\hline Overall Survival & & & & & 0.13 \\
\hline Dead & 18 & $03(17.0)$ & $07(39.0)$ & $08(44.0)$ & \\
\hline Alive & 122 & $49(40.0)$ & $42(35.0)$ & $31(25.0)$ & \\
\hline
\end{tabular}

Table 3: Association of clinicopathological parameters with p53 expression

\begin{tabular}{|c|c|c|c|c|c|}
\hline & & No. of patients & Negative $(\leq 10 \%)$ & Positive (>10\%) & \\
\hline & & $\mathrm{N}=182$ & n (\%) & n (\%) & \\
\hline \multicolumn{2}{|c|}{ Variables } & & & & P-value \\
\hline \multicolumn{2}{|l|}{ Age } & & & & 0.16 \\
\hline & $\leq 40$ years & 52 & 42 (81.0) & $10(19.0)$ & \\
\hline & $>40$ years 130 & $90(69.0)$ & 40 (31.0) & & \\
\hline \multicolumn{2}{|c|}{ Tumor size/ stage } & & & & 0.19 \\
\hline
\end{tabular}




\begin{tabular}{|c|c|c|c|c|}
\hline & No. of patients & Negative $(\leq 10 \%)$ & Positive (>10\%) & \\
\hline & $N=182$ & n (\%) & n (\%) & \\
\hline $\mathrm{T} 1$ & 39 & 32 (82.0) & $07(18.0)$ & \\
\hline T2, T3, T4 143 & $100(70.0)$ & $43(30.0)$ & & \\
\hline Lymph node stage & & & & 0.006 \\
\hline $\mathrm{N} 1$ & 67 & $57(85.0)$ & $10(15.0)$ & \\
\hline $\mathrm{N} 2, \mathrm{~N} 3$ & 115 & $75(65.0)$ & $40(35.0)$ & \\
\hline Histologic grade & & & & 0.02 \\
\hline 1 & 45 & $39(86.0)$ & $06(14.0)$ & \\
\hline 2,3 & 137 & $93(68.0)$ & $44(32.0)$ & \\
\hline LVI & & & & 0.77 \\
\hline Absent & 74 & $55(74.0)$ & $19(26.0)$ & \\
\hline Present 108 & $77(71.0)$ & $31(29.0)$ & & \\
\hline \multicolumn{5}{|l|}{ FOLLOW UP } \\
\hline Disease Recurrence & & & & 0.0001 \\
\hline Present 20 & $03(15.0)$ & $17(85.0)$ & & \\
\hline Absent 120 & $89(74.0)$ & $31(26.0)$ & & \\
\hline Overall Survival & & & & 0.002 \\
\hline Dead & 18 & $06(33.0)$ & $12(67.0)$ & \\
\hline Alive & 122 & $88(72.0)$ & $34(28.0)$ & \\
\hline
\end{tabular}

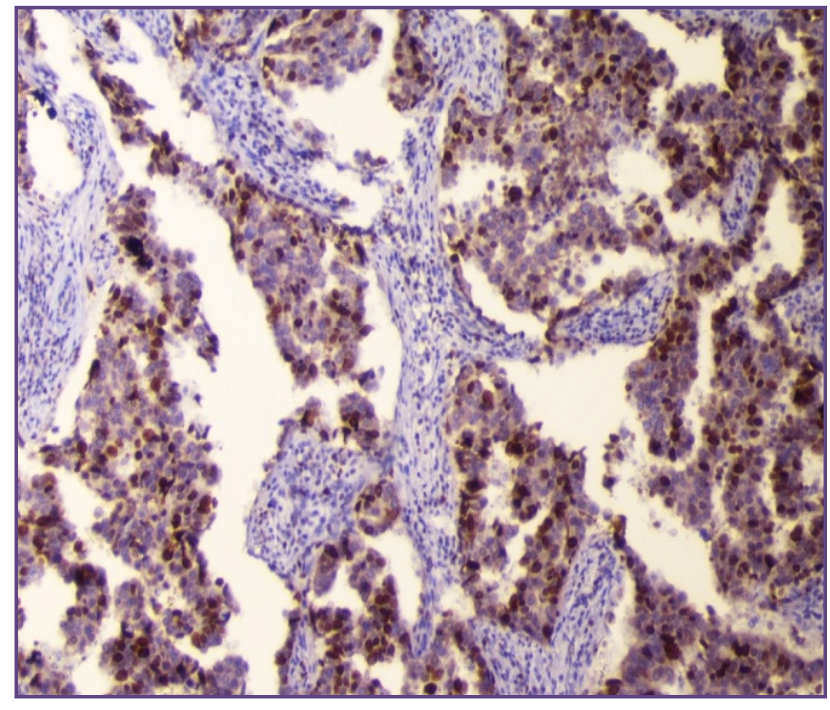

Fig. 1: Infiltrative ductal carcinoma (NOS) with high Ki-67 expression (Grade 3). IHC Ki-67x 40X.

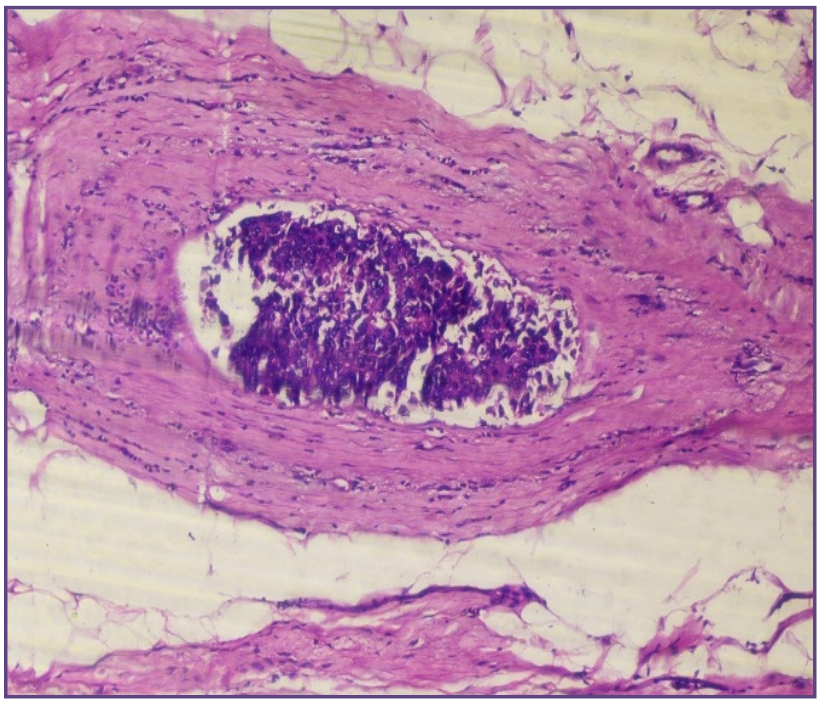

Fig. 2: Breast carcinoma with vascular invasion of tumor cells. Hematoxylin and Eosin $\mathrm{x}$ 40X. 


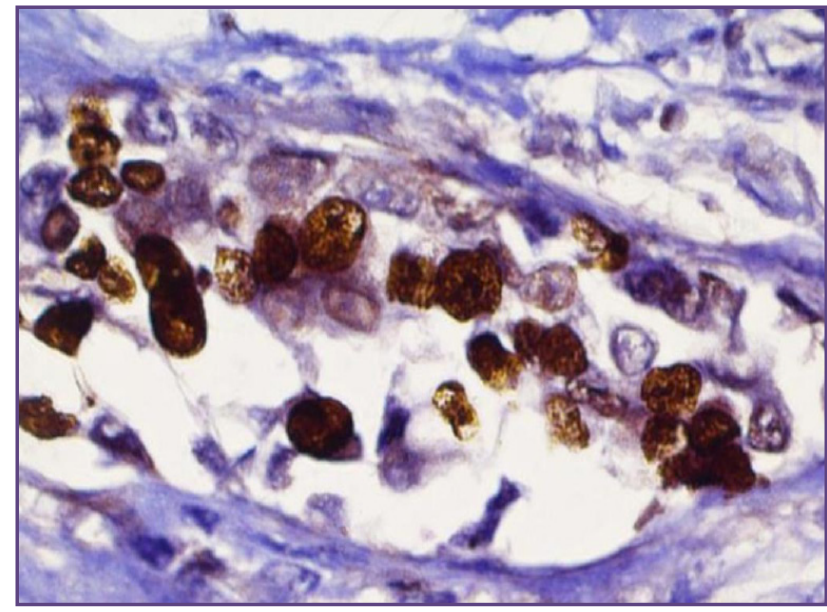

Fig. 3: Breast carcinoma with vascular invasion with high Ki-67 expression. IHC Ki-67 x40X.

\section{Discussion}

About 2/3rd patients were in advanced cancer stage with four or more positive lymph nodes attributable to small sample size, late clinical presentation, poor public awareness about the disease symptoms and inability to afford the cost of treatment. In sub-continental setup, majority of the breast cancer patients are subjected to surgical and chemotherapeutic intervention, but only few of them turn up for follow up, causing significantly lower rates of disease-free and overall survival than breast cancer patients with negative nodes.[13,14]

Almost $10-20 \%$ of these patients develop early disease relapse and metastatic behaviour despite their tumor size and hormone receptor status being known.[15] Individualised treatment and categorical work up of these groups of non-responsive breast carcinoma patients through their early identification is a burning topic in breast cancer research. Prognostic markers are of immense significance with regards to targeted therapy especially, Ki-67 being a marker to proliferative capability of malignant cells. So actually, the Ki-67 positively stained cell population is the growth fraction which is the proportion of actively cycling cells within a defined population.[16]

This study highlights the finding that lymph node metastasis in cases of breast carcinoma influences Ki-67 immunoexpression significantly and patients with higher Ki-67 immunoexpression had worse OS and shortened disease free survival, similar to earlier studies.[17,18] Increased Ki-67 positivity seen in cases with higher number of axillary nodes involved ( $>4$ positive axillary lymph nodes) was an independent prognostic factor for shorter disease free survival and OS, with a cut off value of $14.0 \%$ significantly associated with early disease recurrence $(\mathrm{p}<0.05)$ but not with OS.[19] Ki-67 immunoexpression

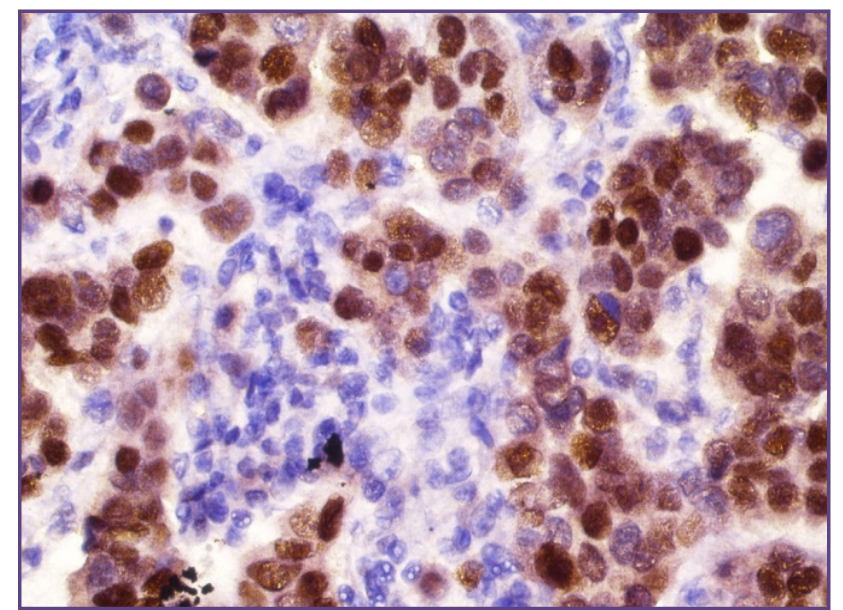

Fig. 4: Infiltrative ductal carcinoma (NOS) with high positive p53 immunoexpression (Grade 3). IHC p53 x40X.

was significantly higher in grade 3 tumors as compared to grade 2 and grade 1 tumors, similar to Wojnar et al.[19] On evaluating relationship of Ki-67 expression with other clinicopathologic characteristics and known prognostic variables of breast carcinoma, it was found that higher Ki-67 expression was statistically significantly associated with increasing age, higher histologic grade, greater tumor size/stage $(\mathrm{T})$, higher nodal stage $(\mathrm{N}$; axillary lymph node positivity) and presence of lymphovascular invasion $(p<0.05)$, similar to previous studies.[15,19,20] Many studies also reported similar findings and supported the association of $\mathrm{Ki}-67$ with poor survival, thus indicating a need for an individualised therapy.[21-23] Crabb et al also found that breast cancer patients with $>4$ axillary nodes involved showed higher Ki-67 immunoexpression and thus correlated with poorer overall survival.[24]

This study showed that p53 expression increased with age, but was not statistically significant. This was similar to previous studies who found no correlation of p53 expression with age, menopausal status, family history and histologic subtypes.[15,25,26] Shokouh et al found p53 positive carcinomas chiefly in women aged above 50 years with no statistical correlation.[27] There was a strong association between nuclear p53 expression and higher histologic grade of breast carcinomas in our study. In addition, the data indicated that the percentage of p53 positive cells in high-grade carcinomas was much higher as compared to grade 1 tumors, similar to previous studies. $[18,28]$ Various studies like have shown statistically significant association between higher tumor grade and p53 expression, thus signifying that $\mathrm{p} 53$ positive tumors tend to be poorly differentiated leading aggressive behaviour and worse outcome.[12,29,30] 
p53 expression increased with metastatic axillary lymph nodes and showed a significant statistical association with Nodal stage $(\mathrm{p}<0.05)$ similar to Yamamoto et al and Payendeh et al who showed that percentage of metastatic nodes was significantly higher in tumors with high p53 expression compared those with lower expression.[31-32]

On evaluating correlation between $\mathrm{p} 53$ immunoexpression and survival, it was seen higher disease recurrence and overall survival was statistically significantly associated with $\mathrm{p} 53$ expression in axillary lymph node positive breast carcinomas $(p<0.01)$ with higher expression in cases showing recurrent/metastatic disease and patients who succumbed early. Kobayashi et al in their study found p53 as a significant prognostic factor for disease free survival and overall survival.[33] Ross et al showed that immunohistochemical detection of 5 markers including p53 was significantly associated with patient survival and clinical outcome.[34] Our data indicated that patients with favourable phenotype (Ki-67 low and p53 negative) tend to survive longer and experienced lesser incidence of recurrence/metastasis.

\section{Conclusions}

Prognosis of lymph node positive breast cancers tend to be poor and potential biomarkers like Ki-67 and p53 can predict the disease free survival and overall survival, as they play an important role in prognostication in node positive breast cancer patients. Future work should be focussed on standardisation of Ki-67 expression and specification of its role in treatment decisions.

\section{References}

1. American Cancer Society. Breast Cancer Facts \& Figures 2017-2018. Atlanta: Am Cancer Soc Inc 2017; 1-5.

2. Malvia S, Bagadi SA, Dubey US, Saxena S. Epidemiology of breast cancer in Indian women. Asia Pacific J Clin Oncol 2017; 13(4):289-295.

3. Murthy NS, Chaudhry K, Nadayil D, Agarwal UK, Saxena S. Changing trends in incidence of breast cancer: Indian scenario. Ind J Cancer 2009; 46(1):73-75.

4. Kim SI, Cho SH, Lee JS, Moon HG, Noh WC, Youn HJ et al. Clinical relevance of lymph node ratio in breast cancer patients with one to three positive lymph nodes. Br J Cancer 2013; 109(5):1165-1167.

5. Urruticoechea A, Smith IE, Dowsett M. Proliferation marker Ki-67 in early breast cancer. J Clin Oncol 2005; 23(28):7212-7220.

6. Gerdes J, Schwab U, Lemke H, Stein H. Production of a mouse monoclonal antibody reactive with a human nuclear antigen associated with cell proliferation. Int J Cancer 1983; 31(1):13-20.
7. Goldhirsch A, Wood WC, Coates AS, Gelber RD, Thürlimann B, Senn HJ et al. Strategies for subtypesdealing with the diversity of breast cancer: highlights of the St Gallen International Expert Consensus on the Primary Therapy of Early Breast Cancer 2009. Ann Oncol 2011; 22(8):1736-1747.

8. Cavanaugh AH, Hempel WM, Taylor LJ, Rogalsky V, Todorov G, Rothblum LI et al. Activity of RNA polymerase I transcription factor $\mathrm{UBF}$ blocked by $\mathrm{Rb}$ gene product. Nature 1995; 374(6518):177-180.

9. Barbareschi M, Caffo O, Veronese S, Leek RD, Fina P, Fox $\mathrm{S}$ et al. Bcl-2 and p53 expression in node-negative breast carcinoma: a study with long-term follow-up. Hum Pathol 1996; 27(11):1149-1155.

10. Dowsett M, Nielsen TO, A'Hern R, Bartlett J, Coombes $\mathrm{RC}$, Cuzick J et al. Assessment of Ki67 in breast cancer: recommendations from the International Ki67 in Breast Cancer working group. J Nat Cancer Inst 2011; 103(22):1656-1664.

11. Tan QX, Qin QH, Yang WP, Mo QG, Wei CY. Prognostic value of Ki67 expression in HR-negative breast cancer before and after neoadjuvant chemotherapy. Int J Clin Exper Pathol 2014; 7(10):6862-6863.

12. Milićević Z, Bajić V, Živković L, Kasapović J, Andjelković U, Spremo-Potparević B et al. Identification of p53 and its isoforms in human breast carcinoma cells. Sci World J 2014; 618698:10-20.

13. Inwald EC, Klinkhammer-Schalke M, Hofstädter F, Zeman F, Koller M, Gerstenhauer M et al. Ki-67 is a prognostic parameter in breast cancer patients: results of a large population-based cohort of a cancer registry. Breast Cancer Res Treat 2013; 139(2):539-552.

14. Yan J, Liu XL, Han LZ, Xiao G, Li NL, Deng YN et al. Relation between Ki-67, ER, PR, Her2/neu, p21, EGFR, and TOP II- $\alpha$ expression in invasive ductal breast cancer patients and correlations with prognosis. Asian Pac J Cancer 2015; $16(2): 823-829$.

15. Ohara M, Matsuura K, Akimoto E, Noma M, Nishizaka T, Kagawa N et al. Prognostic value of Ki67 and p53 in patients with estrogen receptor-positive and human epidermal growth factor receptor 2-negative breast cancer: Validation of the cut-off value of the Ki67 labeling index as a predictive factor. Mol Clin Oncol 2016; 4(4):648-654.

16. Liu S, Edgerton SM, Moore DH, Thor AD. Measures of cell turnover (proliferation and apoptosis) and their association with survival in breast cancer. Clin Cancer Res 2001; 7(6):1716-1723.

17. Madani SH, Payandeh M, Sadeghi M, Motamed H, Sadeghi E. The correlation between Ki-67 with other prognostic factors in breast cancer: A study in Iranian patients. Ind J Med Paed Oncol 2016; 37(2):95-96.

18. Pan Y, Yuan Y, Liu G, Wei Y. P53 and Ki-67 as prognostic markers in triple-negative breast cancer patients. PloS One 2017; 12(2):12-13. 
19. Wojnar A, Kobierzycki C, Krolica A, Pula B, Podharska OM, Dziegeil P et al. Correlation of the Ki-67 and the MCM2 proliferative markers with the grade of the histological malignancy $(\mathrm{G})$ in ductal breast cancers. Folia Histochem Cytobiol 2010; 48(3): 442-446.

20. Xue C, Wang X, Peng R, Shi Y, Qin T. Distribution, clinicopathologic features and survival of breast cancer subtypes in Southern China. Cancer Sci 2012; 103: 16791687.

21. Yang P, Du CW, Kwan M, Liang SX, Zhang GJ. The impact of p53 in predicting clinical outcome of breast cancer patients with visceral metastasis. Sci Rep 2013; 3:46-47.

22. de Bono JS, Tolcher AW, Rowinsky EK. The future of cytotoxic therapy: selective cytotoxicity based on biology is the key. Breast Cancer Res 2003; 5: 154- 159

23. Tawfik K, Kimler BF, Davis MK, Fan F, Tawfik O. Ki67 expression in axillary lymph node metastases in breast cancer is prognostically significant. Hum Pathol 2013; 44: 39-46.

24. Crabb SJ, Bajdik CD, Leung S, Speers CH, Kennecke H. Can clinically relevant prognostic subsets of breast cancer patients with four or more involved axillary lymph nodes be identified through immunohistochemical biomarkers? A tissue microarray feasibility study. Breast Cancer Res 2008;10: 6-8.

25. de Azambuja E, Cardoso F, de Castro G, Jr., Colozza M, Mano MS et al. Ki-67 as prognostic marker in early breast cancer: a meta-analysis of published studies involving 12,155 patients. Br J Cancer 2007; 96: 1504- 1513.

26. Matsubara N, Mukai H, Itoh K, Nagai S. Prognostic impact of Ki-67 overexpression in subgroups categorized according to St. Gallen with early stage breast cancer. Oncol 2011; 81: 345-352.

27. Shokouh TZ, Ezatollah A, Barand P. Interrelationships between Ki67, HER2/neu, p53, ER, and PR status and their associations with tumor grade and lymph node involvement in breast carcinoma subtypes: retrospective-observational analytical study. Med 2015; 94(32):1359-1360.

28. Jacquemier J, Charafe-Jauffret E, Monville F, Esterni B, Extra JM, Houvenaeghel $G$ et al. Association of GATA3, P53, Ki67 status and vascular peritumoral invasion are strongly prognostic in luminal breast cancer. Breast Cancer Res 2009; 11(2):23-24.

29. Silvestrini R, Benini E, Daidone MG, Veneroni S, Boracchi $\mathrm{P}$, Cappelletti $\mathrm{V}$ et al. p53 as an independent prognostic marker in lymph node-negative breast cancer patients. J Nat Cancer Inst 1993; 85(12):965-970.

30. Han JS, Cao D, Molberg KH, Sarode VR, Rao R, Sutton LM et al. Hormone receptor status rather than HER2 status is significantly associated with increased $\mathrm{Ki}-67$ and p53 expression in triple-negative breast carcinomas, and high expression of Ki-67 but not p53 is significantly associated with axillary nodal metastasis in triple-negative and highgrade non-triple-negative breast carcinomas. Am J Clin Pathol 2011; 135(2):230-237.

31. Yamamoto M, Hosoda M, Nakano K, Jia S, Hatanaka KC, Takakuwa E et al. p53 accumulation is a strong predictor of recurrence in estrogen receptor positive breast cancer patients treated with aromatase inhibitors. Cancer Sci 2014; 105(1):81-88.

32. Payandeh M, Sadeghi M, Sadeghi E, Madani SH. Expression of p53 breast cancer in Kurdish women in the West of Iran: a reverse correlation with lymph node metastasis. Asian Pac J Cancer Prev 2016; 17(3):1261-1264.

33. Kobayashi T, Iwaya K, Moriya T, Yamasaki T, Tsuda H, Yamamoto $\mathrm{J}$ et al. A simple immunohistochemical panel comprising 2 conventional markers, Ki-67 and p53, is a powerful tool for predicting patient outcome in luminal-type breast cancer. BMC Clin Pathol 2013; 13(1):5-6.

34. Ross DT, Kim CY, Tang G, Bohn OL, Beck RA, Ring BZ et al. Chemosensitivity and stratification by a five monoclonal antibody immunohistochemistry test in the NSABP B14 and B20 trials. Clin Cancer Res 2008; 14(20):6602-6609.

*Corresponding author:

Dr Kafil Akhtar, Professor, Department of Pathology, Jawaharlal Nehru Medical College, Aligarh Muslim University, Aligarh. (U.P)-India.

Phone: +91 9568467727

Email: drkafilakhtar@gmail.com.

Financial or other Competing Interests: None. 